\title{
Mapping Cumulative Environmental Risks: Examples from the EU NoMiracle Project
}

\author{
Alberto Pistocchi - Jan Groenwold • Joost Lahr • Mark Loos • Marelys Mujica • \\ Ad M. J. Ragas - Robert Rallo • Serenella Sala • Uwe Schlink - Kathrin Strebel • \\ Marco Vighi - Pilar Vizcaino
}

\begin{abstract}
We present examples of cumulative chemical risk mapping methods developed within the NoMiracle project. The different examples illustrate the application of the concentration addition (CA) approach to pesticides at different scale, the integration in space of cumulative risks to individual organisms under the CA assumption, and two techniques to (1) integrate risks using data-driven, parametric statistical methods, and (2) cluster together areas with similar occurrence of different risk factors, respectively. The examples are used to discuss some general issues, particularly on the conventional nature of cumulative risk maps, and may provide some suggestions for the practice of cumulative risk mapping.
\end{abstract}

\footnotetext{
A. Pistocchi $\cdot$ P. Vizcaino

European Commission Joint Research Centre,

Via E.Fermi,

1-21027 Ispra, VA, Italy

J. Groenwold $\cdot$ J. Lahr

Alterra, Wageningen UR,

P. $O$. Box 46,6700 AA Wageningen, The Netherlands

M. Loos · A. M. J. Ragas

Department of Environmental Science, Institute for Water and Wetland Research, Radboud University Nijmegen,

Heyendaalseweg 135 ,

6525 AJ Nijmegen, The Netherlands

M. Mujica $\cdot$ R. Rallo

Departament d'Enginyeria Química i Departament d'Enginyeria

Informatica i Matematiques, Universitat Rovira i Virgili,

Av. Paisos Catalans, 26,

43007 Tarragona, Catalonia, Spain
}

Keywords Cumulative environmental risk .

GIS mapping - Mixtures - Multiple stressors · Pesticides . Metals $\cdot$ Spatial distribution

\section{Introduction}

Over the last few years, there has been an increasing interest in the representation of chemical risks for purposes such as decision support, risk communication, and scientific research. As mapping technologies become more and more routinely used, attention for the underlying methods of risk mapping and visualization is growing (e.g., $[2,13$,

S. Sala $\cdot$ M. Vighi

Department of Environmental Sciences,

Universita' di Milano Bicocca,

Piazza della Scienza l,

20126 Milan, Italy

U. Schlink $\cdot$ K. Strebel

Helmholz Centre for Environmental Research-UFZ,

Permoserstrasse 15,

04318 Leipzig, Germany

Present Address:

A. Pistocchi

Ewopean Academy,

Viale Druso,

1-39100 Bolzano, Italy

e-mail: alberto.pistocchi $\hat{a}$ eurac.edu 
$20,31,60,61])$. Lahr and Kooistra $[28,29]$ recently categorized the different types of risk maps that exist and reviewed the methods to make them. They distinguish, among others, between maps of contamination, (potential) exposure, vulnerability, and "true risk" for single or multiple stressors.

In general, risk is determined by the concurrence of chemical pollution and vulnerable receptors (e.g., organisms, populations, communities, ecosystems, ecosystem resources, and services). Both can be mapped. In the past, pollutant concentrations were often used as a proxy for risk on maps. It was implicitly assumed that vulnerable receptors were homogeneously distributed over the analysis area, generally owing to the lack of information on the spatial distribution of these receptors. However, receptor vulnerability is increasingly being included in spatial analyses of risk (e.g. $[10,21$, $32,49]$ ). Maps that show the spatial distribution of vulnerable receptors are called vulnerability maps, e.g., ground water vulnerability maps (e.g., [47, 62]).

True risk can be defined as "the probability of an adverse effect on man or the environment resulting from a given exposure to a chemical or mixture" [53]. Tiue risk can be calculated from the combination of exposure and receptor vulnerability. The mapping of true risk caused by a single pollutant is conceptually straightforward, although practical problems are posed by lacking or incomplete data, the consideration of multiple exposure pathways, and the mobility of receptors. Additional problems may arise when considering cumulative risks, i.e., those arising from multiple chemicals acting as a mixture or chemicals together with other (non-chemical) stressors such as aridity, climate, or land use change. Risks may be posed to single as well as multiple receptors, and exposure of (mobile) receptors may vary between different micro-environments.

Lahr and Kooistra $[28,29]$ discuss the most important issues in risk mapping and provide some general rules of thumb for making environmental risk maps for communication purposes. One of the limitations they identify is that only one or very few parameters can be represented on a single map. This particularly poses problems for cumulative risk maps which by definition have to deal with multiple parameters, and are increasingly a subject of interest in chemical pollution management (e.g., $[22,54]$ ). The most applied solution to this problem is to express the overall risk in terms of a single indicator and to map the outcome, although examples exist of maps that visualize multiple parameters simultaneously $[28,29]$. Despite the interest in cumulative risk mapping, little guidance exists about which methods to adopt in different circumstances. Spatially distributed chemical risk assessment remains a conceptually complex procedure, although tools for spatially explicit modeling are increasingly available and attractive (see, e.g., the discussion in [38]). As a complement to Lahr and
Kooistra's critical review, we present here a range of methods for the analysis and presentation of cumulative risks which were recently developed and applied within the European NoMiracle project (http://nomiracle.jrc.ec.europa. eu). By comparing the different methods, we aim at providing the reader with some general insights and guidelines for analyzing and mapping cumulative risks.

We first identify a range of appropriate methods for cumulative risk assessment. These include models of mixture toxicity, models of variable exposure, data-driven risk mapping, and classification (or clustering) techniques based on known risk factors. Then, the different methods are presented one by one through examples. We finally propose summary considerations, which may help practitioners in need of mapping cumulative chemical risks. The methods we deal with, and the examples we use, are summarized in Table 1.

\section{Materials and Methods}

A widely used scheme to characterize the combined action of multiple chemical substances is that of Bliss [5], further developed by Plackett and Hewlett [39]. Stemming from that scheme, two different approaches to modeling mixture toxicity are typically used, the concentration addition (CA) and the independent action (IA) models [17]. The CA approach assumes that different chemicals act together as their respective sum. Concentrations should be added up just after appropriate normalization. One way to do so is to divide them by a comparable threshold concentration, such as the widely used $50 \%$ effect concentration $\left(\mathrm{EC}_{50}\right)$. The IA approach assumes that the overall response of an ecosystem to a mixture of chemicals is the sum of responses to individual chemicals. The two models are applicable to chemicals with the same mode of action or to chemicals with different modes of action respectively.

Assuming that environmentally relevant mixtures have heterogeneous mechanisms of action, a two-stage prediction approach (TSP) was developed [24] by combining the CA and IA models. Conceptually, the TSP approach is the best to assess pesticide mixtures that can be expected to be neither strictly similarly nor strictly dissimilarly acting. Taking into account that the mixture responses calculated using the CA model are usually higher than those calculated with the IA model, CA can be assumed as a conservative but "reasonable" worst case $[6,12,14,16,24]$.

The metric of potential ecotoxic risk for chemical mixtures under the $\mathrm{CA}$ assumption are the toxic units (TU) of the mixture:

$\mathrm{TU}_{m}=\sum_{i=1}^{n} \mathrm{TU}_{i}=\sum_{i=1}^{n} \frac{C_{i}}{\mathrm{EC}_{x, i}}$ 
Table 1 Summary of the features of the methods presented in the paper

\begin{tabular}{|c|c|c|c|c|c|}
\hline Method & Cumulative aspect & Example presented & Underlying approach & Target of risk & $\begin{array}{l}\text { Measure of risk } \\
\text { presented in the map }\end{array}$ \\
\hline $\begin{array}{l}\text { Method 1: models of } \\
\text { mixture toxicity }\end{array}$ & $\begin{array}{l}\text { Mixture of chemicals acting } \\
\text { together }\end{array}$ & $\begin{array}{l}\text { Mixtures of pesticides at European, } \\
\text { national, and regional scale }\end{array}$ & $\begin{array}{l}\text { Deterministic calculation of } \\
\text { PECs with GIS; concentration } \\
\text { addition model }\end{array}$ & Ecosystems (generic) & $\begin{array}{l}\text { Toxic units. Potential } \\
\text { exposure }\end{array}$ \\
\hline $\begin{array}{l}\text { Method 2: variable } \\
\text { exposure modeling }\end{array}$ & $\begin{array}{l}\text { Exposure of individuals to } \\
\text { different chemicals unevenly } \\
\text { distributed in space }\end{array}$ & $\begin{array}{l}\text { Exposure to heavy metals related } \\
\text { to foraging behavior in a Dutch } \\
\text { floodplain }\end{array}$ & $\begin{array}{l}\text { Receptor-oriented agent-based } \\
\text { modeling }\end{array}$ & $\begin{array}{l}\text { Ecosystems (specific } \\
\text { organisms) }\end{array}$ & $\begin{array}{l}\text { Hazard quotient for } \\
\text { individual organisms. } \\
\text { "True risk" }\end{array}$ \\
\hline $\begin{array}{l}\text { Method 3: data-driven } \\
\text { risk mapping }\end{array}$ & $\begin{array}{l}\text { Pollution from a mixture of } \\
\text { sources }\end{array}$ & $\begin{array}{l}\text { Ambient air-borne benzene in } \\
\text { Leipzig }\end{array}$ & $\begin{array}{l}\text { Regression involving risk } \\
\text { factors and spatial auto- } \\
\text { correlation }\end{array}$ & Human health & $\begin{array}{l}\text { Chemical concentration. } \\
\text { Contamination }\end{array}$ \\
\hline $\begin{array}{l}\text { Method 4: classification } \\
\text { based on known (a priori) } \\
\text { risk factors }\end{array}$ & $\begin{array}{l}\text { Different factors concuring to } \\
\text { natural resource vulnerability }\end{array}$ & Aquifer vulnerability in Catalonia & SOM classification & Aquifer & Vunerability \\
\hline
\end{tabular}

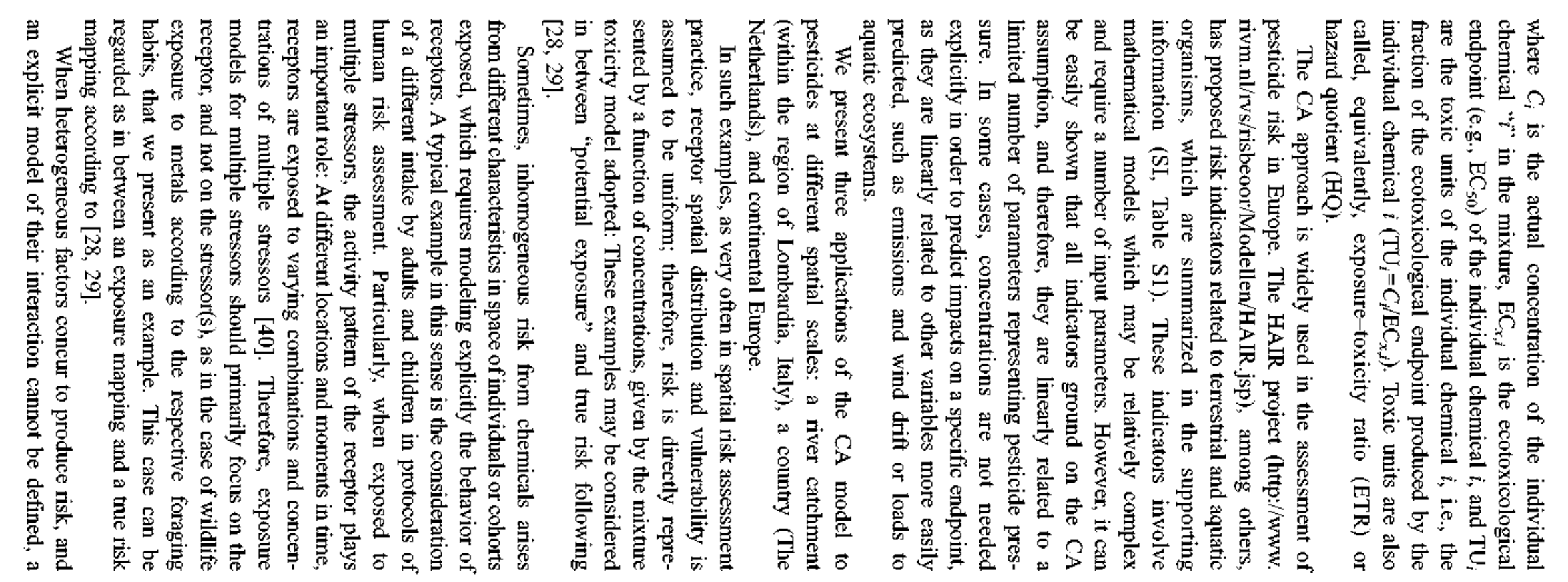


"data driven" approach should be adopted. One example is provided about mapping risk due to benzene in air in Leipzig, Germany. In that case, a risk indicator is defined (benzene concentration), and a statistical model involving the most relevant explanatory factors is applied to interpolate point measurements to a continuous representation of the risk indicator. For the specific example, we assume concentration as a proxy of risk, therefore neglecting the variability of receptor conditions. According to Lahr and Kooistra $[28,29]$, then this is an example of a contamination map.

When no information on actual impacts is available, one may still combine different risk factors based on prior knowledge. Combinations may be rule-based classifications, or alternatively ground on formal clustering techniques. Among the latter, the Self Organizing Map (SOM) technique [27] is an unsupervised neural network algorithm that projects (classifies) high-dimensional data into a two or three-dimensional grid of units (clusters) while preserving the original topology of the input space and facilitating the visualization of hidden patterns present in the data [27]. SOM units are organized on a regular hexagonal lattice that defines the neighboring structure of the map units. The algorithm is based on competitive learning $[25,26,58]$ where units gradually become sensitive to different input categories of the input space.

The SOM is a powerful clustering tool that has demonstrated to be appropriate for the classification and visualization of complex datasets including highly nonlinear relationships. The component planes (C-planes) are the most important analysis and visualization tools since they provide the distribution over the map of the values corresponding to each component of the input data vectors. Straightforward correlations and relationships in the input dataset can be found by simultaneously comparing several C-planes [57]. The clustering structure of the input space is visualized using the unified distance matrix (U-matrix), which is constructed by measuring the distances between all units in the map. The U-matrix is usually post-processed by clustering its components to produce coarser data partitions. We present an application of this technique through the example of aquifer vulnerability to pollution in Catalonia, Spain.

\section{Examples of Cumulative Environmental Risk Mapping}

\subsection{Concentration Addition}

As a first example, we refer to the distribution of agricultural pesticides in Europe. Screening level maps of pesticide mass in soil and load to streams in Europe are available $[35,37]$. These maps are linearly related to predicted environmental concentrations as used in the HAIR indicators and therefore can be directly expressed using the CA concept. The predicted mass in soil and load to streams for each substance class, represented each time by its "most dangerous chemical," has been used in a weighted summation, so to express, in terms of toxic equivalents to one substance, total mass and load as a cumulative risk indicator for terrestrial and aquatic ecosystems.

Unfortunately, currently available data on pesticides for Europe are limited to chemical substance classes and not to individual pesticides within each class. Therefore, for the sake of illustration, we assumed that each chemical substance class is composed of the most dangerous chemical of the class, selected as the one having the lowest toxicity threshold within its class. We retrieved physicochemical and toxicological properties for the active substances within each class from the FOOTPRINT online Pesticide Properties Data Base (PPDB) (www.en-footprint. eu). The weights of the generic $j$-th chemical, $v_{j}$ and $w_{j}$, used to sum together mass in soil and load to streams for different chemicals can be estimated as:

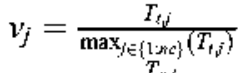

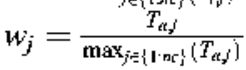

where $T_{x, j}(x=t, a)$ is the toxicity threshold (no observed effect concentration (NOEC), 50\% lethal concentration ( $\left(\mathrm{CC}_{50}\right)$, or similar metrics) of chemical $j$, for terrestrial and aquatic ecosystems, respectively, while nc is the number of chemicals considered.

Unfortunately, not for all active substances toxicity data are provided in the database. Terrestrial endpoints are better covered than aquatic ones. Bees represent an endpoint for spray drift only, as they are impacted only by pesticide reaching non-target vegetation and crops. For soil ecology, earthworms are a more representative endpoint. However, chronic toxicity data for earthworms are far less abundant than acute $\mathrm{LC}_{50}$. Table $\mathrm{S} 2$ in the SI shows the percentage of pesticides with toxicity data available, according to the five most common endpoints tested. Although absolute toxicities vary depending on the receptor under consideration, and the temporal span of exposure (acute, chronic), in the absence of more detailed information sometimes, it is assumed that the relative chronic toxicity of substances is reflected by the relative acute toxicity (e.g., [11]).

In the present application, we consider acute toxicity to earthworms for terrestrial organisms, and NOEC at 21 days for aquatic organisms. Table S3 in the SI indicates the most dangerous chemical selected for each chemical class, for terrestrial and aquatic ecosystems, respectively. The same toxicity data are used to derive weights with Eq. 2, also provided in the same table. 
The proposed assessment prospects an indicator of pesticide risk in Europe for aquatic and terrestrial ecosystems for different years, allowing an estimate of trends in the overall risk related to pesticides. The results of these calculations for the year 2003 are shown in Figs. 1 and S1 of the SI, respectively. The two maps highlight the cumulative spatial distribution of pesticides, with reference to two different endpoints (terrestrial and aquatic), taking as reference substances the most toxic ones in the two cases (picoxystrobine, a strobilurine fungicide, and omethoate, an organophosphorus insecticide, respectively). The spatial distribution may be grossly similar, but significant differences arise due to variations in physico-chemical properties of the substances, hence the different weighting for the two endpoints.

Figures 1 and $\mathrm{S} 1$ of the SI highlight potential problem areas or "hot spots" in a specific year (2003). In general, the use of pesticides in Europe is rather widespread; hot spots are predicted in Spain, Italy, France, and The Netherlands. Some countries (like Poland) show extensive presence of medium-high levels. Often hot spots are associated with vineyards, generally bearing the highest pesticide application from the 20 classes considered in this study.

A comparison of maps as shown in Figure S1 of the SI, and Fig. 1, with the corresponding ones for the year 1992 (not shown here for simplicity), yields a picture of the variation in overall risk due to pesticides, with reference to a specific receptor (Fig. 2).

As it appears, the situation in Europe resulting from the example calculation is rather variable in space, showing areas of increase and decrease of overall pressure (load, mass).
In the case of mass in soils, representing pressure on terrestrial ecosystems, there is generally a persistence or increase between 1992 and 2003, while on aquatic ecosystems, there is a general decreasing trend. However, in both cases, important differences arise across regions. The different behavior is linked to the differences in trends in the use of the different substances contributing to the overall toxicity to terrestrial and aquatic endpoints.

It is important to stress that the maps provide the maximum toxic equivalent for a given combination of emissions from the different chemical substance classes. Therefore, the result is in general an upper limit of the cumulative toxicity. The only way to obtain an estimate of the actual cumulative toxic equivalent would be through referring emissions to individual chemicals, of which on the other hand use data are not yet available for Europe. Also, the spatial distribution must be regarded as a realization of the random field of pesticide use, as there is not sufficient information to allocate to each country and crop within a country the corresponding pesticide use. The method just outlined is applied to map the overall impact of pesticides on terrestrial and aquatic organisms in Europe. A similar approach can be extended to other risk indicators, and particularly to human health risk; this is anyway beyond the scope of the example presented here.

When the assessment does not concern general trends only, but requires higher realism, the temporal as well as spatial distribution of pesticide emissions needs to be taken into account to reflect realistic field conditions.

A second example deals with region-specific risks of pesticide mixtures [41]. It relates to water bodies in a pilot

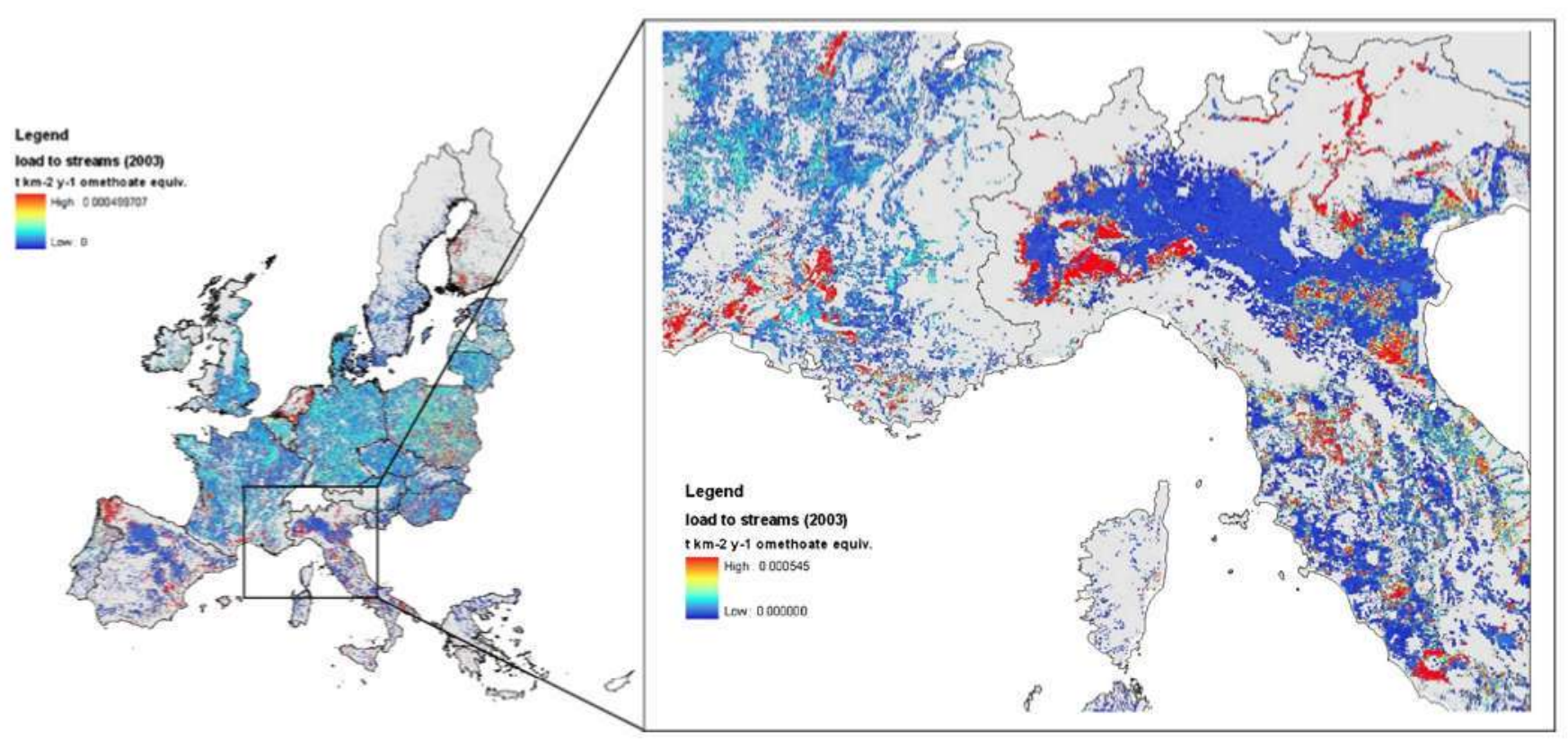

Fig. 1 Example map of load equivalent (criterion, 21 days NOEC aquatic invertebrates) 

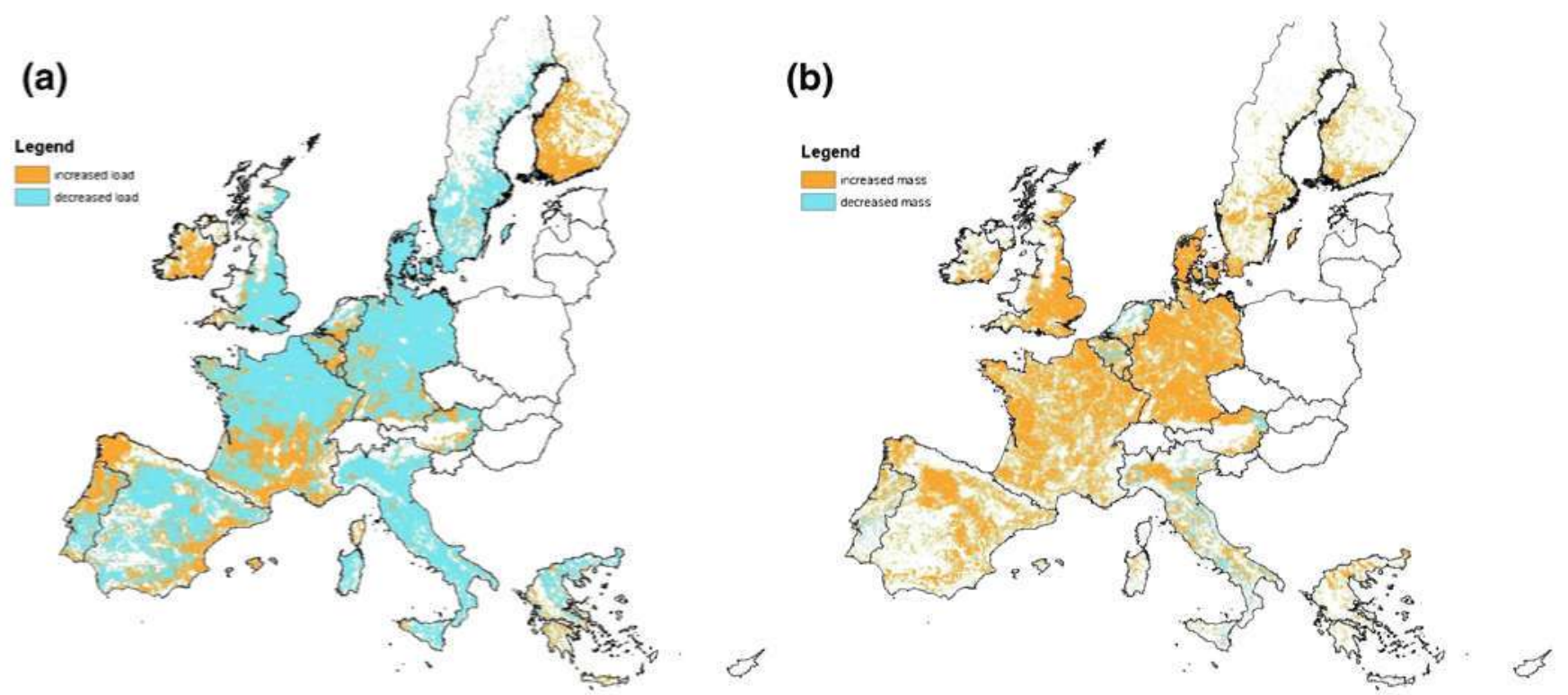

Fig. 2 Areas of increased/decreased pesticide load to streams (a) and mass in soil (b), expressed in omethoate equivalent and picoxystrobine equivalent, respectively

agricultural area (Oltrepo Pavese, in the southern part of the River Po basin in the Lombardia Region, Northern Italy), considering pesticide runoff and drift processes. The area includes seven river basins of tributaries of the River Po. Four herbicides (alachlor, terbuthylazine, metholachlor, and pendimethalin) have been selected in this case study as they are the most widely used pesticides applied on maize (the main crop in the area).

The distribution of predicted environmental concentrations (PECs) in surface water due to a single drift or runoff event for individual chemicals can be mapped at different resolution, using maps of environmental parameters (land use and crop distribution, application rate, river flows, etc.) at appropriate scale using well established procedures [41]. The four selected herbicides are applied in the same period (late April). Figure 3 shows the spatial distribution of the PECs produced by runoff after the first rain event after application. The basins of the seven rivers have been divided into sub-basins characterized by relatively homogeneous environmental parameters. The distribution of PECs reflects climate and landscape differences among basins and sub-basins (rain, crop distribution and density, slope, water flow, etc.), as well as different application rates and properties of the chemicals, and in this case, it can be considered reliable and also pointwise. Crop density and slope are the major driving forces responsible for herbicide
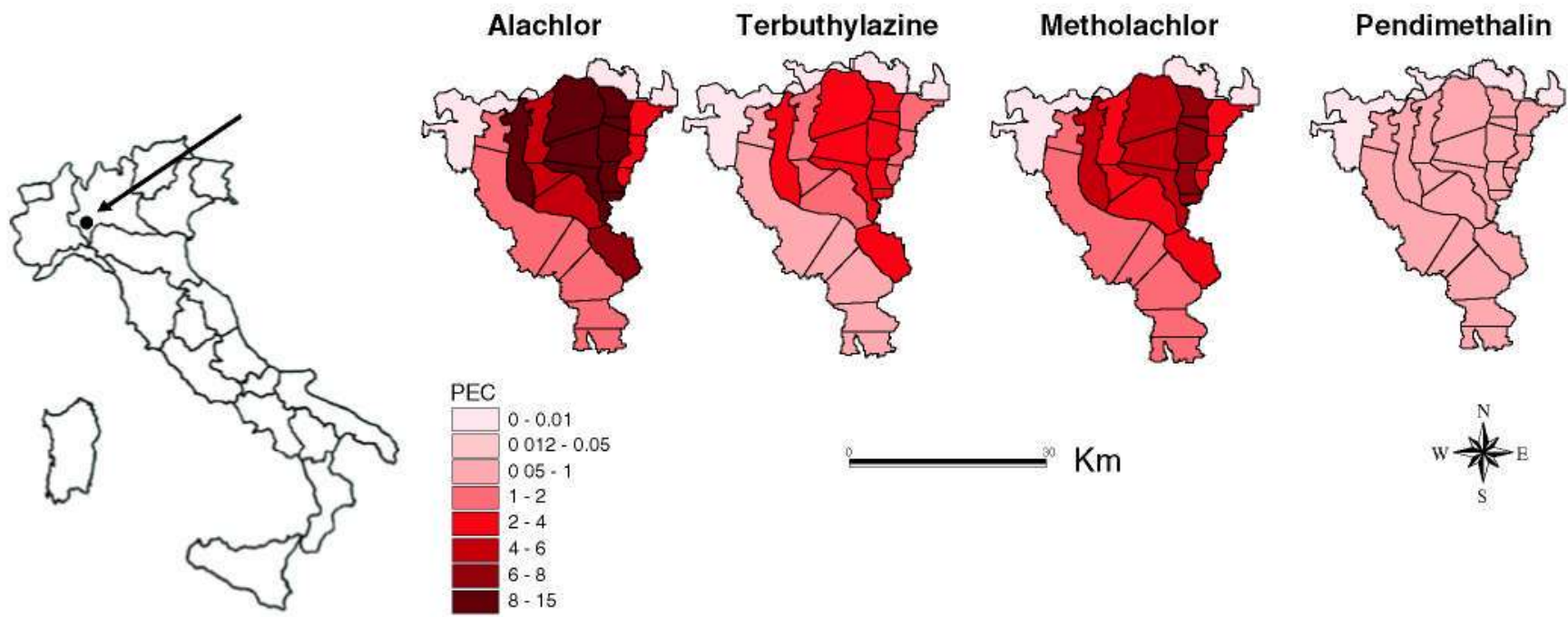

Fig. 3 Map of PECs (in $\mu \mathrm{g} / \mathrm{l}$ ) studying surface water for the selected herbicides due to runoff in the first rain event after application 
runoff in surface water. The risk due to the mixture of the four selected herbicides was calculated with the $\mathrm{CA}$ approach. In Fig. 4, the risk for algae, calculated from $96 \mathrm{~h} \mathrm{EC}_{50}$, is shown as an example. The mixture toxicity map shows that in some basins, a potential risk for acute toxicity may occur. Considering the relative contribution of individual components of the mixture, alachlor and terbutylazine account for more than $80 \%$ of the total mixture toxicity.

The calculation conducted in the example can be applied to more complex mixtures, including possibly all pesticides used in a given agricultural area, and can be repeated for each significant emission event (rain events or drift corresponding to application). Moreover, the cumulative risk for all the components of the aquatic community (plants, invertebrates, and fish) can also be estimated by applying suitable risk indices for the biological community [15]. An example of application and validation of the procedure for the description of the time variability of PECs for individual chemicals is reported by Bonzini et al. [7]. A complete assessment of mixture composition from all the pesticides used in a pilot area during the whole productive season is reported by Verro et al. [55, 56].

As a third example, we consider the Dutch Environmental Indicator model for plant protection products, notably pesticides (denoted by the Dutch acronym NMI: $[50,52]$ ) developed jointly by the Dutch National Institute for Public Health and the Environment (RIVM) and Alterra, Wageningen UR. This method is used to evaluate the impact of national pesticide reduction policies. We will show some results of NMI calculations for three test pesticides: chlorpyrifos, imidacloprid, and diazinon. The NMI was used to demonstrate the potential environmental impact of

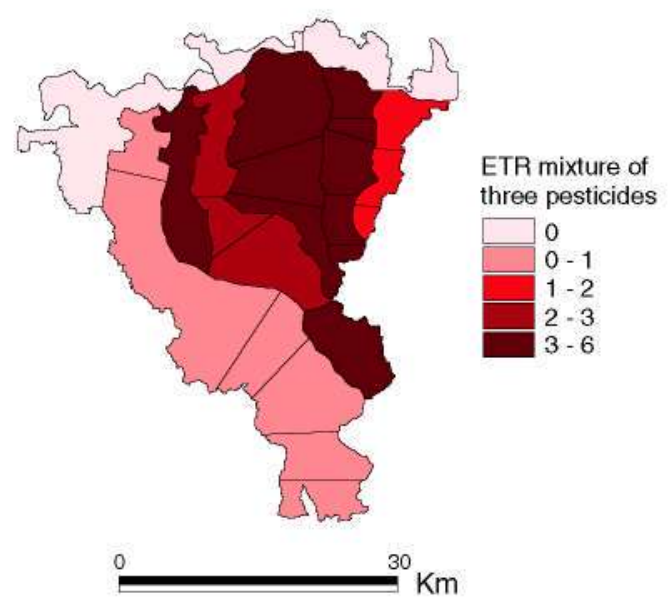

Fig. 4 Map of distribution of ETR for algae or TU, calculated for the mixture of the selected herbicides corresponding to the first rain event after application the separate substances and the substances combined for the year 1998 and to explore some of the visual possibilities of NMI maps (see Supporting information).

The NMI estimates emission of pesticides to air, groundwater and surface water, potential acute and chronic effects on soil and water organisms, and potential contamination of drinking water by leaching to ground water. Based on crop data, the results of NMI calculations can be visualized for particular years in maps with 25 -ha grid cells.

If one is interested in emission figures, for example for emission reduction programs, calculations can be focused on emissions rather than on potential ecological effects. Figure 5 shows the emissions in 1998 of atrazine, a herbicide that has since been banned in the Netherlands. The map shows where emission reduction measures are most urgent and will be most effective in terms of total national use. The map may be combined with a histogram showing the total number of grid cells in the country with emissions in certain categories. The histogram can be used to evaluate the amount of grid cells that are (still) above a certain threshold level, for example an emission of $1 \mathrm{~kg}$ atrazine per grid cell (Fig. 5).

Estimated environmental concentrations are also divided by environmental effect concentrations such as $\mathrm{EC}_{50}$ values. This yields TU values which are used as indicators of risk. For groundwater, estimated concentrations are normalized through the legislative standard for drinking water. In the NMI environment, this type of quotient, as well as the TU values for aquatic and terrestrial organisms, are jointly called environmental indicator units (EIU).

As in the previous examples, potential cumulative environmental impact can be evaluated with the CA assumption, i.e., by adding the EIU values. If one is interested in the overall environmental potential impact of chemical compounds, maps can be made as shown in Fig. 6. This map shows for the three test insecticides where in The Netherlands the EIU values for one of the indicators (aquatic, terrestrial, and drinking water) for a single substance exceeds 1. However, it also shows where the EIU for combinations of pesticides may exceed 1 (pink areas; it only occurred for combinations of imidacloprid and chlorpyrifos). These are additional risk areas that would not show up on a map for single pesticides.

The examples from the NMI presented here and in the Supporting information demonstrate some of the ways in which risks of pesticides can be displayed at a national scale. It is possible to visualize risks of single substances but also risks of several substances in one map. However, one is always limited by the number of categories that can be displayed in a single map. This is determined by the number of different colors that people can reasonably distinguish. So, the chosen display depends on the objective of the maps and the kind of information that needs to be 
Fig. 5 Potential emission to surface water of the herbicide atrazin in 1998 calculated by the NMI
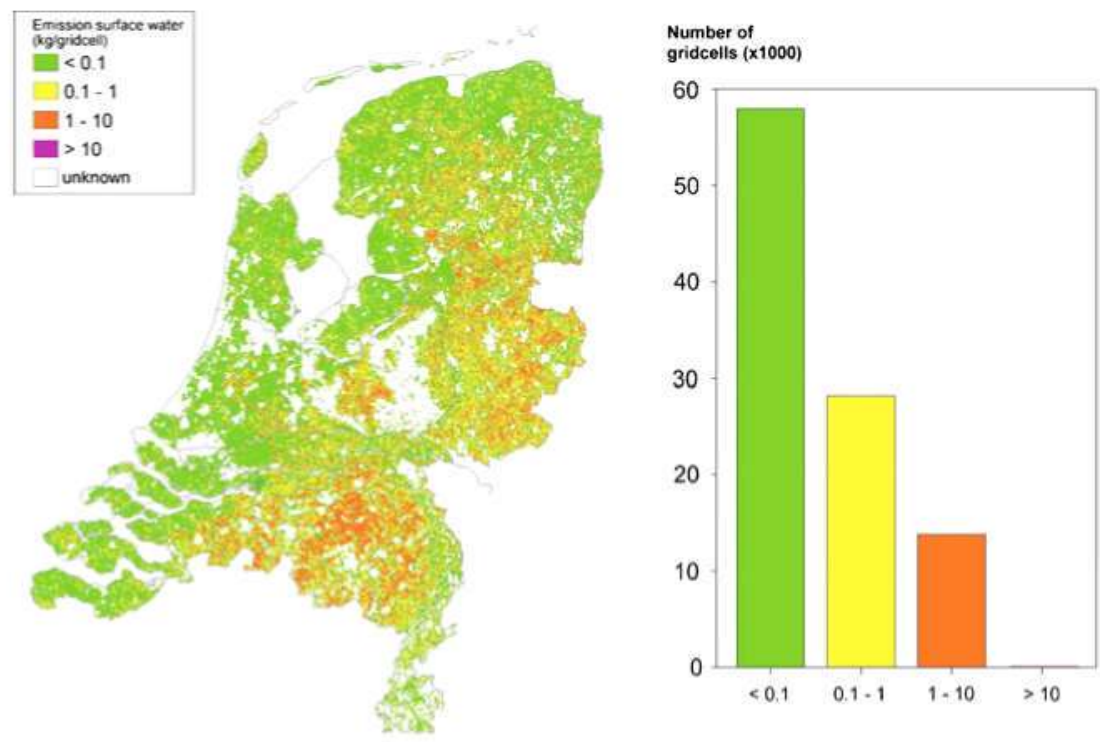

passed on to the users. Combination of emission or risk maps with other visualization methods such as graphs (Fig. 5) provides a powerful tool for communicating to decision makers, for instance when designing pesticide reduction schemes (e.g., [51]).

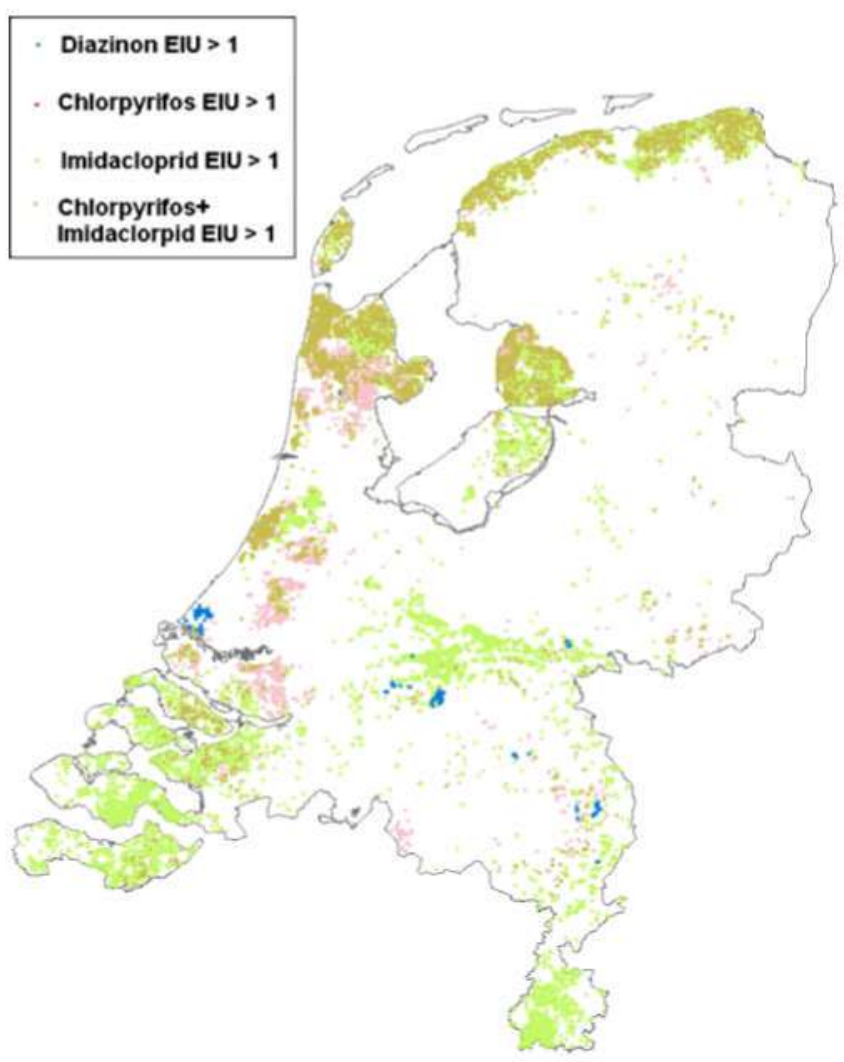

Fig. 6 Overall risk for three insecticides (chlorpyrifos, imidacloprid, and diazinon) in The Netherlands in 1998 assessed with the NMI. EIU are calculated by dividing PECs by threshold concentrations
3.2 Local Risk Mapping Based on Receptor-Oriented Modeling: An Example of Wildlife Exposure to Heavy Metals

This example presents a cumulative risk map that is a result of cumulative risk estimates of heavy metals for wildlife species using the receptor-oriented wildlife exposure model SpaCE $[30,43]$, grounding on the $C A$ approach as discussed above. Such a receptor-oriented model simulates the exposure pattern of receptors based on their individual characteristics, e.g., the spatial foraging behavior, food preferences, and physiology (i.e., feeding rate). SpaCE consists of three main modules. The landscape module comprises the spatial input data for the model, i.e., speciesspecific habitat maps and maps of the contaminant concentrations in soil. The latter were made by inverse distance weighted (IDW) interpolation of point data, i.e., chemical soil concentrations measured in the study area. Further, the foraging module simulates the spatial foraging behavior. Movement algorithms simulate the receptor over a rasterized habitat map during the course of its life starting from a "nest" location. Finally, the exposure module simulates the contaminant flow in the food web. The internal contaminant concentrations in food items of the receptors (i.e., soil dwelling invertebrates, gastropods, and vegetation) are calculated using empirical relations, relating the internal contaminant concentrations to the concentrations in the soil. The lifetime average exposure concentration in food is calculated for each contaminant and every individual receptor obeying food web relations and depending on the local contaminant concentrations in the available food items encountered during the foraging. These PECs are compared with the predicted no effect concentrations in food (the threshold concentration) by computing HQs to 
determine the risk from each contaminant. After this normalization, the risks are added up following the Concentration Addition approach (Eq. 1).

The cumulative risks for the individual receptors are plotted on a map as point estimates, where the nest location is used as the location to allocate the receptor. All risk point estimates (representing a population of multiple individuals) are then converted to a raster output. In this procedure, the same cell size of the soil contaminant concentration maps need to be assigned to the movement simulation model grid: In case more than one individual was modeled in one cell, the mean of the risk values of these individuals was assigned to the cell. To cover the whole area where the receptor species reside, the IDW interpolation method was applied for assigning risk values to cells in which no individuals were modeled.

In a case study in the Afferdensche and Deestsche Waarden floodplain in the Netherlands, 225,000 common shrew individuals were modeled in their suitable habitat. Assuming concentration addition, their cumulative risk to $\mathrm{Cd}, \mathrm{Ni}$, and $\mathrm{Zn}$ is shown in Fig. 7, through the coupling of a cartographic display with pie charts, effective for conveying proportion [19]. Color is an important visual attention guide and influences risk perception [59]. The level of risk (expressed as HQ) is visualized according to the risk hierarchy for color (i.e., red riskier than yellow, yellow riskier than green) found by Sattler et al. [42].

For comparison, risks from individual stressors are shown in Fig. 8. A receptor-oriented model, such as $\mathrm{SpaCE}$, is an effective approach for addressing cumulative risk and can be used for risk mapping purposes. SpaCE estimates risk for receptors for substances that do not interact and in areas were these receptors forages (i.e., in suitable habitat). By simulating multiple individuals per

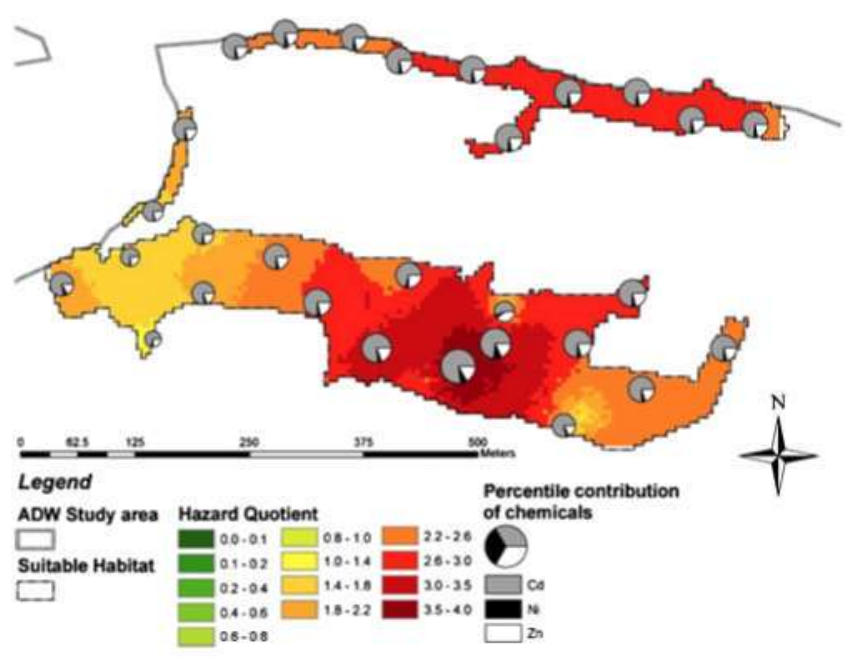

Fig. 7 Cumulative risk (HQ) of cadmium, nickel, and zinc, assuming concentration addition, to the common shrew (Sorex araneus L.) in a part of the Afferdensche en Deetsche Waarden study area nest location, the model can be used to estimate and map the variation around the risk as a result of foraging behavior.

As the SpaCE model estimates the risk for mobile receptors, there is some uncertainty involved in the mapping of their risk; it involves a choice of allocating the risk onto a map. The predicted risk is actually a result of foraging behavior within the home range (i.e., represented by a rectangular area around the nest location). But, the home ranges overlap, making it difficult to map risk per home range onto a raster layer. Since the risk of an individual can be interpreted as the home range average risk and the nest location is always located at the center of the home range, it is considered justifiable to assign the risk of an individual to its nest location using the coordinates of the nest to plot the risk.

\subsection{Data-Driven Risk Mapping: An Example on Air-Borne Benzene in Leipzig}

The example presented here is based on measurements of ambient benzene concentrations at 191 dwellings in the city of Leipzig, Germany. Each site was sampled one time for a period of about 4 weeks (from January 2001 to April 2002).

To protect human health, in Germany, a limit for air pollution with benzene is set to $5 \mu \mathrm{g} / \mathrm{m}^{3}$ [4]. Not exceeding this threshold, the median value of the measured benzene concentrations in Leipzig is $1.29 \mu \mathrm{g} / \mathrm{m}^{3}$, similar to other German cities like Erfurt (median $1.62 \mu \mathrm{g} / \mathrm{m}^{3}$ ) or Hamburg (median $1.13 \mu \mathrm{g} / \mathrm{m}^{3}$ ) [45]. Srivastava et al. [46] observed in residential areas in the mega city of Delhi, India, a mean benzene concentration that is about ten times higher. The mean predicted benzene concentration for the city of Leipzig in December is $2.36 \mu \mathrm{g} / \mathrm{m}^{3}$. Jo et al. [23] measured in residential areas in Daegu, South Korea during winter a geometric mean that is about three times higher than the predicted mean for Leipzig in December.

We observed a seasonal cycle in ambient benzene concentrations, with lower levels in summer than in winter, comparable to the results by Hansen and Palmgren [18]. Pekey and Arslanbas [33] found lower ambient benzene concentrations in summer than in winter in urban areas, offices, and schools. A comparable seasonal cycle of concentrations was observed by Schlink et al. [44] for indoor volatile organic compounds.

The measurements were processed using Bayesian inference. With a generalized linear regression, assuming a log-normal distribution of benzene concentrations, we take into account spatial correlation between the sampled sites $[3,48]$. In this way, space is explicitly included in risk assessment. From a set of factors those with significant impact to the concentration were identified (Fig. 9), namely, (1) the factor "Land use" describing the type of land use, 
Fig. 8 Risk of cadmium, nickel, and zinc common shrew (Sorex araneus L.) in a part of the Afferdensche en Deetsche Waarden study area
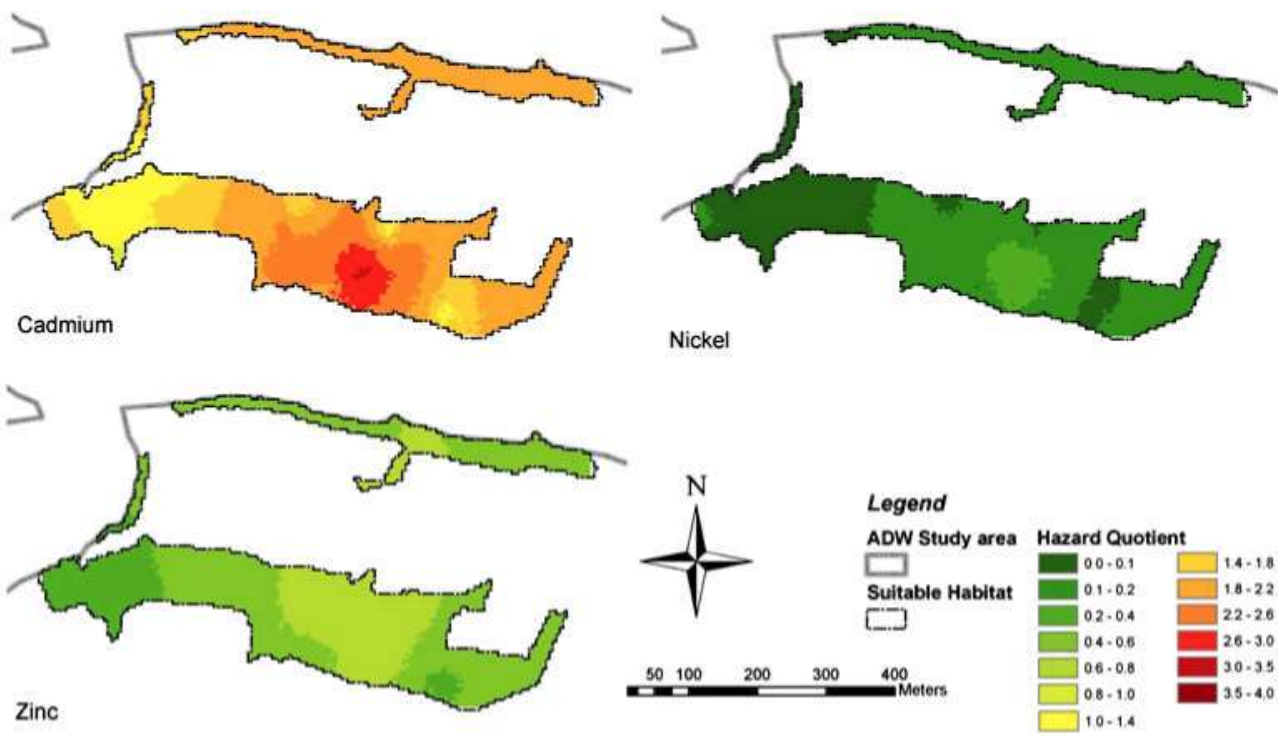

i.e., green, water, agricultural, forest, residential, or industrial area; (2) "Traffic intensity" representing the traffic intensity; (3) "Bft" as a measure for the wind velocity; (4) "DistToCentr" representing the distance to the city center $[\mathrm{km}]$; and (5) NE, SE, SW, and W for the frequency of winds coming from directions north-east, south-east, south west, and west, respectively. The values of the meteorological factors (Bft, NE, SE, SW, and $\mathrm{W}$ ) are varying temporally; the values of the geographical factors (Others, TrafficNo50m, and DistToCentre) are varying spatially. The model was generally adjusted for the month of measurement. Model output was the monthly predicted benzene concentration at grid points with spacing $500 \mathrm{~m}$ for the city of Leipzig. Spatial interpolation yielded in geographical maps representing the continuous benzene concentration field (for December see Fig. 10).
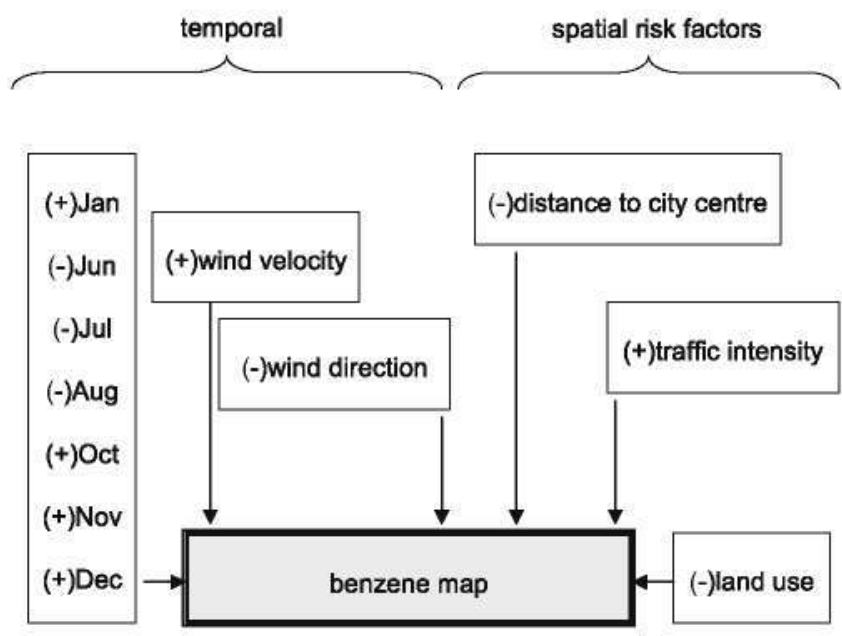

Fig. 9 Temporal and spatial risk factors with significant impact to the benzene concentration that were used for mapping (the sign indicates whether the factor has a positive or negative influence)
The statistical model provides a multiplicative decomposition of the cumulated risk into parts that are attributable to the individual factors (Fig. 10). In detail, we find that the higher Traffic or Bft, the higher benzene concentration. With increasing DistToCentre, the ambient benzene concentration is getting lower. The more often wind comes from NE, SE, SW, or W, the lower is the benzene concentration. The benzene pollution level varies with season and is significantly higher during winter (October to January) than in summer (May and June).

The spatial variation of benzene concentration in the maps for December is caused by the spatially varying impact factors. The high concentration around the city center corresponds to high traffic intensity, land use, and short distance to the city center. The influence of the traffic intensity is also reflected in the hot spots at the drive ups to the motorway in the north-east of Leipzig.

This statistical technique allows the consideration of scenarios of different severity: Median benzene concentration levels (Fig. 9, middle) reflect the ordinary case scenario. They are high in and around the city center, where traffic intensity is higher than in the peripheral regions of the city. In the north-east, there are three hot spots that are situated at drive ups to a motorway. In the worst-case scenario (Fig. 9, right hand side) - based on the 95th percentile of the predictions - the maximal benzene concentration is nearly twice as high as it is for the ordinary case scenario. If benzene concentrations come up to the values predicted in the worst-case scenario, an acute health risk at places around the concentration hot spots cannot be excluded. The location of concentration hot spots of the worst case agree with the ordinary case. From the best-case scenario (Fig. 9, left hand side), concentration hot spots are not identifiable. Spatial variation of the concentrations is rather limited; there is just background pollution all over 

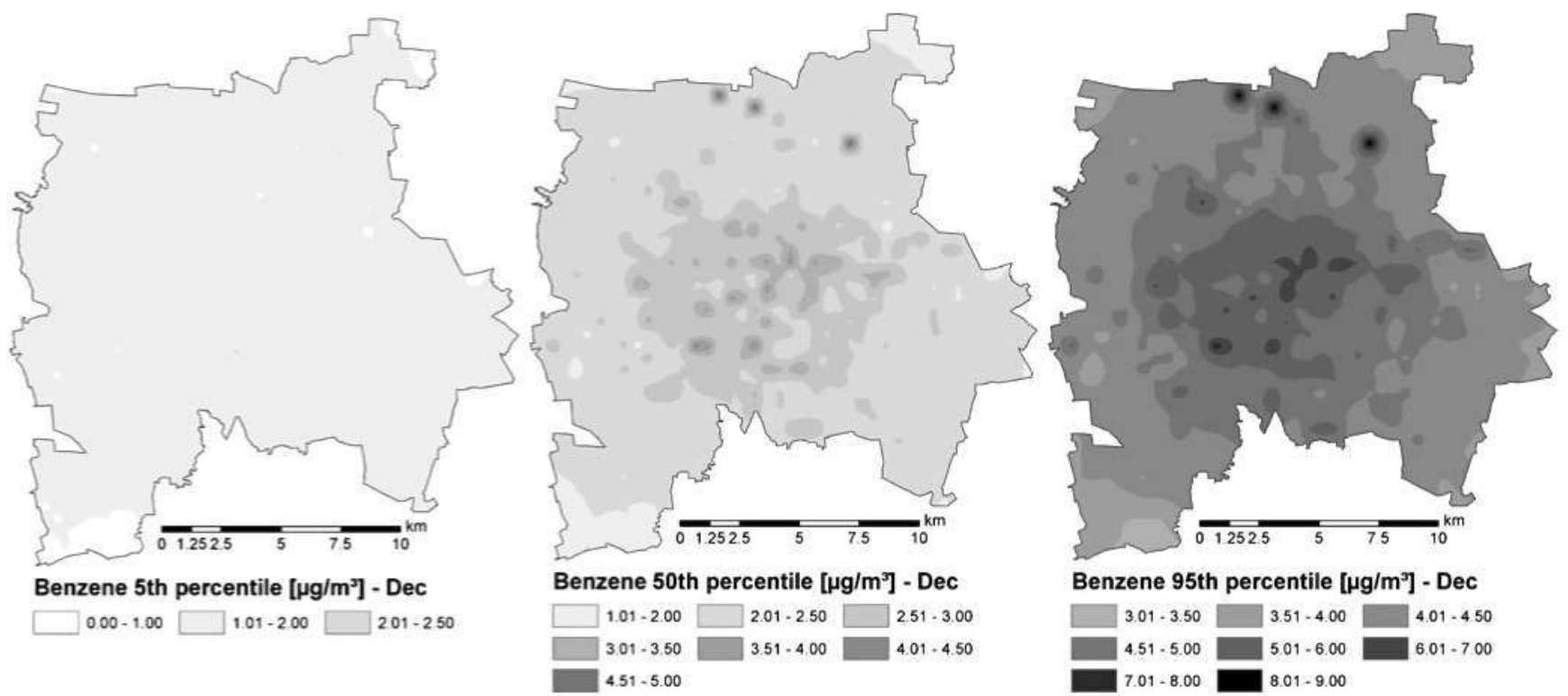

Fig. 10 Predicted benzene concentration field for the city of Leipzig, Germany in December. Best-case scenario, 5th percentile (left hand side); ordinary case scenario, 50th percentile (middle); worst-case scenario, 95th percentile (right hand side)

the town. The range of variation of the concentration is lowest for the best and highest for the worst-case scenario.

\subsection{Classification Based on Known Risk Factors:}

Groundwater Vulnerability Mapping Using Self-organizing Maps

Our society is increasingly aware of the environmental status of aquifers since they provide one of the most important sources of potable water. The continuous emission of anthropogenic pollutants into the aquifer reduces water quality and may eventually threaten our drinking water supply.

The assessment of groundwater vulnerability is usually performed on the basis of vulnerability indicators reflecting individual factors affecting vulnerability, combined in order to obtain a comprehensive and synthetic characterization of the actual aquifer vulnerability. A widely used and wellknown method is the DRASTIC index, developed by the US Environmental Protection Agency (EPA) as a standardized system [1]. The DRASTIC index is obtained by the weighted sum of seven hydrogeological properties, i.e., depth to water table $(D)$, net recharge $(R)$, aquifer media $(A)$, soil media $(S)$, topography $(T)$, impact of the vadose zone $(I)$, and hydraulic conductivity of the aquifer $(C)$ as:

$$
\text { DRASTIC index }=5 D+4 R+3 A+2 S+T+5 I+3 C
$$

The seven hydrogeological variables are usually represented in maps, after transformation by rating each variable with values between 1 and 10 . The variables increase with increasing vulnerability of the aquifer. The construction of maps for the seven variables requires extensive assessment, based on expert judgment and specific data described in detail in Aller [1].

We present an example for Camp de Tarragona, a hydrogeologic unit located in the southeast of Catalonia close to the Mediterranean Sea. It includes three counties, covers an area of $406 \mathrm{~km}^{2}$, and has a dynamic economy with very important industrial, commercial, touristic, and agricultural activities. It includes two important cities, Tarragona and Reus, an airport, and an industrial harbor.

In the current study, the depth to water table was generated by kriging interpolation of the 315 piezometric data points available over region studied. Net recharge was calculated from the values of annual rainfall, land surface slopes, and soil permeability [34], which were accessible all in detail for whole area considered. Aquifer media information was obtained from complete geological maps, while soil media information was generated by kriging interpolation of only 123 infiltration capacity data points within Spain. Topography was obtained by processing a detailed digital terrain model with GIS. The impact of the vadose zone was calculated by linear combination of soil permeability and depth to water table [34]. Finally, the hydraulic conductivity parameter was inferred from the geological map by considering typical values of saturated hydraulic conductivity for the two dominant geological formations of rock type and grain size that exist in the Camp de Tarragona. The model of Eq. 3 is parametric, as it relies on weights for the different factors assigned a priori based on previous experience. 
Here, we show how an automated classification method as the SOM procedure may be used when the a priori knowledge is not sufficient to apply parametric models to develop a vulnerability map of groundwater. Figure 11 illustrates the SOM-based vulnerability methodology applied to map aquifer vulnerability over the Camp of Tarragona area in Catalonia. At the left side of Fig. 11 are the trained SOM's C-planes for each variable, SOM U-matrix, and the DaviesBouldin clustering [58] of the SOM units. The vulnerability map for the Camp of Tarragona based on SOM classification of the seven DRASTIC input parameters of the hydrogeological area is presented at the right side of Fig. 11. The optimal SOM configuration for this data corresponds to a hexagonal sheet map composed of 2,542 units with quantization and topological errors of 0.009 and 0.023 , respectively.

Visual inspection of the SOM's C-planes reveals the presence of some correlations between variables, e.g., in the case of the parameters depth to water $(D)$ and impact of the vadose zone $(I)$. The distribution of high and low values over the C-planes are quite similar; the right area of the map has lower values than the left area for both parameters. Comparison of the net recharge $(R)$ and the topography $(T)$ reveals certain correlation in the high level values, especially at the lower part of the map. These correlations observed in the C-planes are evidence of the capability of SOM to find relations between variables because, as explained before, parameter $I$ was calculated from $D$ and $S$ [34], where $D$ is the most influential factor in the calculation. Also, parameter $R$ is calculated from values of rainfall, soil's permeability $(S)$, and soil's slopes $(T)$ [34].

The U-matrix reveals the limits of cluster units indicated by the distance between values in adjacent neurons. In the U-matrix legend, red color indicates the highest Euclidean distance and thus represents cluster borders, while blue color indicates closer units representing compact areas. The Davies-Bouldin [58] index was used to select the optimal number of clusters based in an optimized $K$-means partition of SOM units. Five clusters were identified by the DaviesBouldin index and labeled applying DRASTIC weights to data of each cluster center. Blue color was assigned to lower cluster value and red color to high cluster value, ranging from low vulnerability impact to high vulnerability impact in five distinctive classes.

\section{Discussion and Conclusions}

When considering mixtures of chemicals, a viable approach is to develop an explicit toxicity model. In practical

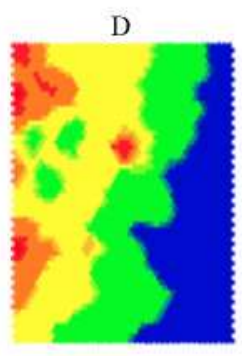

S

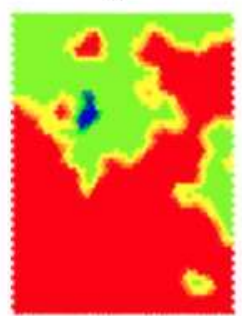

C

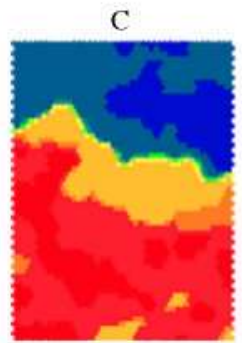

$\mathrm{R}$

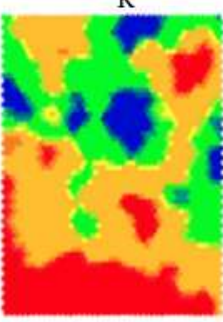

$\mathrm{T}$
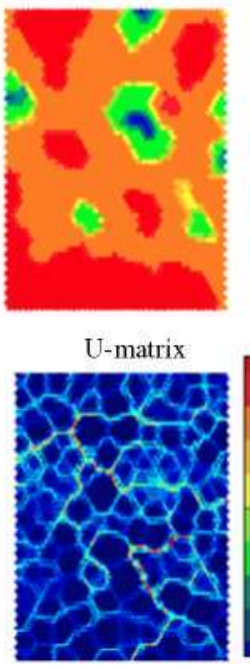

A

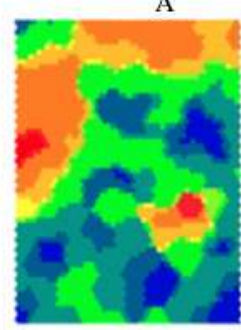

I

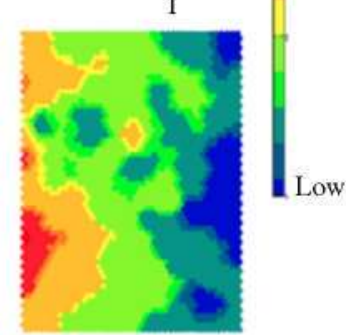

Davies-Bouldin p.on Clustering
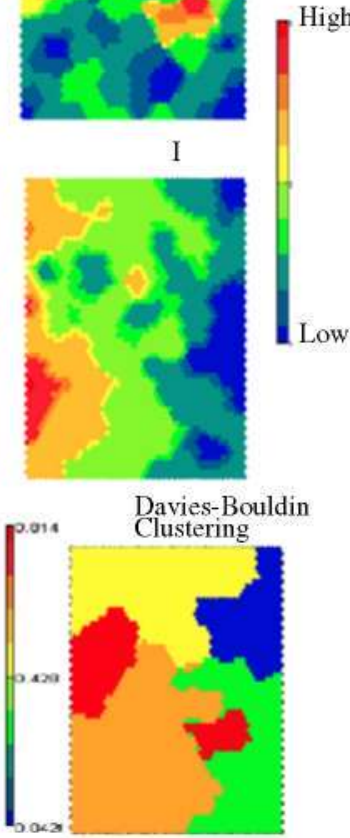

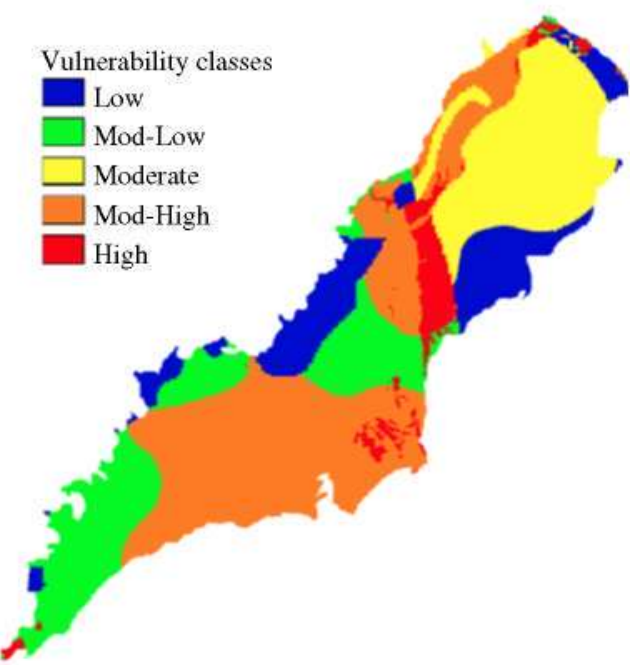

Fig. 11 SOM-based DRASTIC vulnerability index for the Camp de Tarragona area. ( $D$ depth to water, $R$ net recharge, $A$ aquifer media, $S$ soil media, $T$ topography, $I$ impact of the vadose zone, $C$ hydraulic conductivity of the aquifer) 
applications, the CA approach provides a reasonable basis of assessment, although in principle more rigorous methods might be applied. Pesticides provide a representative example of substances often generating pollution, hence risks, through their combination in mixtures. Although conceptually straightforward and computationally simple, the mapping of cumulative risks under the CA assumption requires reliable mapping of emissions to the environment, prediction of concentrations for individual substances, and knowledge of the relative toxicity in order to compute the mixture toxic units. In some cases, and for specific chemicals, it has been shown that risk mapping can be done at a much more detailed level, by including foraging habits of organisms. In this case, models act as simulators to obtain an estimate of actual exposure, and not just potential exposure as in the cases presented on pesticides, where receptors are assumed to be uniformly distributed.

Methods involving the representation of receptor conditions or behavior, in principle, enable representing true risk but require information additional to the distribution of chemical concentrations, and are therefore typically more specialized and expensive. When no such detailed information is readily available, adopting reasonable safe-side assumptions on receptors may be preferable.

As a risk (contamination, exposure, and true risk) mostly cannot be measured at each location of a map, the observations, made at representative sites, can be interpolated in a reasonable way by data-driven approaches, which identify and involve the most important factors determining this risk, as in the example of benzene. In other cases nonparametric statistical techniques can be used as discussed, e.g., in Chung and Fabbri $[8,9]$. Data-driven techniques have been widely applied in other contexts, for instance in the mapping of geo-environmental hazards (e.g., [36]).

A clustering technique can be applied to areas where no known impact occurred, but a risk is known to be caused by a series of factors; in such cases, areas with similar combinations of these factors can be identified, and this provides a first classification that can be used in decision support. The SOM method yielded continuous vulnerability classes despite the fact that no geographical coordinates were used in the training process. The classification of georeferenced data by SOM and the labeling of the resulting macro-classes yielded vulnerability maps consistent with previous and well-accepted methodologies, such as DRASTIC. Additionally, SOM provides a good basis to select the most suitable set of variables for a specific area of concern since it effectively represents spatial regions of similar multivariable patterns that are identified and characterized by non-linear correlations between variables.

An important issue is the way in which cumulative risk maps are used: Sometimes, spatial distributions are meaningful in a statistical sense (i.e., they provide meaningful values for the mean, median, and percentiles of risk indicators), but the actual values assumed by the map at specific locations might be unreliable. For instance, the estimation of pesticide PECs presented at the European scale is not reliable due to the scale of assessment and the limitations in pesticide emission data, as thoroughly discussed by [35]: Maps represent only a statistically plausible distribution. Therefore, in risk communication, in such cases, it is suggested to avoid referring directly to the maps, but rather to their histograms (statistical parameters), using such addresses as "between 1992 and 2003, about $7 \%$ of European land has decreased toxicity of pesticides in soil" or "between 1992 and 2003 , about $70 \%$ of European land has decreased toxicity of pesticides in stream ecosystems."

A cumulative map integrates the risk from multiple causes together, thus reducing the information to one map. Cumulative aspects of chemical risk arise when considering a mixture of different chemicals and other stressors, a single chemical with multiple sources, a combination of factors determining vulnerability, or a combination of the above circumstances. Cumulative risk maps usually convey one single content: They represent, on a qualitative, ordinal or quantitative scale, the level of risk at each point. Therefore, although largely conventional, they are rather unambiguous, easy to interpret and to convey to non-experts for use in decision support, compared with sets of separate maps for single causes of risk. Moreover, in some cases, they can be repeated at different times (see for example maps of herbicide risk at the local scale in Figs. 3 and 4), producing a picture of risk distribution in space and time. For example, if temporal variability of chemical emissions is known, the temporal variability of mixture composition can also be assessed, as described by Verro et al. [55]. On the other hand, from most of the examples presented in this paper, it appears that mapping cumulative risks is far from being an easy task: methods of cumulative mapping entail simplifications and assumptions that make the final maps usually less certain and robust than maps of individual risks. Cumulative maps should be regarded as practical products to convey information to decision makers, the general public, and other stakeholders. They are not always scientific products to be challenged with experiments and evaluation, but rather the results of conventional representations of which the realism should be always critically evaluated through expert judgment. However, at least at the regional or local scale, where the distribution of critical input data in space and time can be obtained with sufficient detail and reliability, cumulative risk maps may be a sound and practical representation of expected critical areas. When such data are not available in space to the desired level of reliability, if at least the frequency distribution of individual risks can be represented to some reliability, 
computing cumulative maps may still be useful to produce a synthetic interpretation of complex interactions of individual risks.

Acknowledgments This paper contains considerations jointly developed by different partners of the NoMiracle project consortium. The individual case studies presented here are provided by single partners, to which the reader may refer for fiuther details and for all scientific aspects not related to the specific topic of risk mapping: A. Pistocchi and P. Vizcaino for the European mapping of pesticides, $S$. Sala and M. Vighi for the case study on pesticides in Lombardy, $J$, Groenwold and J. Lahr for the one on pesticides in the Netherlands, M. Loos and A. Ragas for the case study on risks to individual organisms, U. Schlink and $\mathrm{K}$. Strebel for the case of benzene in Leipzig, and M. Mujica and R. Rallo for the case on aquifer vulnerability mapping in Catalonia. J. Lahr coordinated the mapping exercises within the fiame of NoMiracle Project work package 4.4, while A. Pistocchi coordinated the writing of the paper. The research was partly funded by the European Commission FP6 contract no. 003956 (NoMiracle IP: http://nomiracle.jrc.ec.ewropa.eu). Funding of Alterra, Wageningen UR, was also obtained from the Strategic research program "Sustainable spatial development of ecosystems, landscapes, seas and regions" financed by the Dutch Ministry of Agriculture, Nature Conservation and Food Quality (LNV).

\section{References}

1. Aller, L., Bennet, T., et al. (1987). DRASTIC, a standardized system for evaluating groundwater pollution potential using hydrogeologic setting. U.S. Environmental Protection Agency, EPA, Report 600/2-87-035; 1-455.

2. Bartels, C. J., \& Van Beurden, A. U. C. J. (1998). Using geographic and cartographic principles for environmental assessment and risk mapping. Joumal of Hazardous Materials, 61, 115-124.

3. Best, N., Richardson, S., \& Elliott, P. (2003) Spatial epidemiology. Short Course, September 8-9.

4. BImSchV, 22 (2007) Verordnung zur Durchführung des BundesImmissionschutzgesetzes (Verordnung über Immissionswerte für Schadstoffe in der Luft). Bundesminister für Unwelt, Naturschutz und Reaktorsicherheit.

5. Bliss, C. I. (1939). The toxicity of poisons applied jointly. The Annals of Applied Biologv, 26, 585-615.

6. Boedeker, W., Drescher, K., Altenburger, R., Faust, M., \& Grimme, L. H. (1993). Combined effects of toxicants: the need and soundness of assessment approaches in ecotoxicology. Science of the Total Environment, 134(2), 931-938.

7. Bonzini, S., Verro, R., Otto, S., Lazzaro, L., Finizio, A., Zanin, G., et al. (2006). Experimental validation of a GIS-based procedure for predicting pesticide exposure in surface water. Environmental Science \& Technologv, 40,7561-7569.

8. Chung, C. F., \& Fabbri, A. G. (1993). The representation of geoscience information for data integration. Nonrenewable Resources, 2(2), 122-139.

9. Chung, C. F., \& Fabbri, A. G. (1999). Probabilistic prediction models for landslide hazard mapping. Photogrammetric Engineering and Remote Sensing, 65(12), 1389-1399.

10. De Lange, H. J., Sala S., Vighi M., \& Faber J. H. (2010) Ecological vulnerability in risk assessment-A review and perspectives. Science of the Total Environment (in press)

11. de Zwart, D. (2005). Ecological effects of pesticide use in the Netherlands: modeled and observed effects in the field ditch. Integrated Environmental Assessment and Management, l(2), $123-134$.
12. Drescher, K., \& Boedeker, W. (1995). Assessment of the combined effects of substances: the relationship between concentration addition and independent action. Biometrics, 51, 716-730.

13. Elliott, P., \& Wartenberg, D. (2004). Spatial epidemiology: current approaches and future challenges. Environmental Health Perspectives, 11?, 998-1006.

14. Faust, M., Altenburger, R., Backhaus, T., Blanck, H., Bödeker, W., Gramatica, P., et al. (2003). Joint algal toxicity of 16 dissimilarly acting chemicals is predictable by the concept of independent action. Aquatic Toxicologv, 63, 43-63.

15. Finizio, A., Calliera, M., \& Vighi, M. (2001). Rating systems for pesticide risk classification on different ecosystems. Ecotoxicology and Environmental Safety, 49, 262-274.

16. Finizio, A., Villa, S., \& Vighi, M. (2005). Predicting pesticide mixtures load in surface waters from a given crop. Agriculture. Ecosystems \& Environment, $111,111-118$.

17. Greco, W., Unkelbach, H. D., Pöch, G., Suhnel, J., Kundi, M., \& Bodeker, W. (1992). Consensus on concepts and terminology for combined-action assessment: the Saariselkä agreement. Archives of Complex Environmental Studies, 4(3), 65-72.

18. Hansen, A. B., \& Palmgren, F. (1996). VOC air pollutants in Copenhagen. The Science of the Total Enironment, 190, 451457.

19. Hollands, J. G., \& Spence, I. (1998). Judging proportion with graphs: the summation model. Applied Cognitive Psvchology, 12, 173-190.

20. Husdal, J. (2001) Can it be that dangerous? Issues in visualization of risk and vulnerability. http $/ /$ husdal.typepad.com/blog/2001/10/ can-it-really-b.html.

21. Ippolito, A., Sala, S., Faber, J. H., \& Vighi, M. (2010) Application of vulnerability analysis; a case study of river basin. Science of the Total Environment (in press).

22. Jarosinska, D. (2009). Protecting human health and ecosystemsconnecting novel research, practice and policy on multiple stressors Proc. NoMiracle/PHIME Conference "Multiple Stressors-Novel Methods for Integrated Risk Assessment" Aarhus, Denmark, 28th-30th September. http://nomiracle.jrc.ec.europa.ed/ Documents/Conference_28-30_September_2009/Proceedings.pdf.

23. Jo, W. K., Lee, J. W. \& Shin, D. C. (2004). Exposure to volatile organic compounds in residences adjacent to dyeing industrial complex. International Archives of Occupational and Environmental Health, 77(2), 113-120.

24. Junghans, M., Backhaus, T., Faust, M., Scholze, M., \& Giimme, L. H. (2006). Application and validation of approaches for the predictive hazard assessment of realistic pesticide mixtures. Aquatic Toxicology, 76, 93-110.

25. Kangas, J. A., Kohonen, T. K., \& Laaksonen, J. T. (1990). Variants of self-organizing maps. IEEE Transactions on Neural Networks, $1,93-99$.

26. Kaski, S. (1997). Data exploration using Self-Organizing Maps. Dissertation for the degree of Doctor of Technology, Helsinki University of Technology, Espoo.

27. Kohonen, T. (1990). The self-organizing map. Proc IEEE, 78, $1464-1480$

28. Lahr, J., \& Kooistra, L. (2009) Environmental risk mapping: state of the art and communication aspects. Science of the Total Environment (in press).

29. Lahr, J., \& Kooistra, L. (2010). Environmental risk mapping of pollutants: state of the art and communication aspects. Science of the Total Environment, doi:10.1026/j.scitotenv.2009.10.045.

30. Loos, M., Ragas, A. M. J., Plasmeijer, M. J., \& Hendriks, A. J. (2010) A receptor-oriented ecological exposure model for terrestrial vertebrates in an object-oriented programming platform. Science of the Total Environment (in press).

31. Moen, J. E. T., \& Ale, B. J. M. (1998). Risk maps and communication. Journal of Hazardous Materials, 61, 271-278. 
32. Nelson, P. (2000). Australia's national plan to combat pollution of the sea by oil and other noxious and hazardous substancesoverview and current issues. Spill Science \& Technology Bulletin, $6,3-11$,

33. Pekey, H., \& Arslanbas, D. (2008). The relationship between indoor, outdoor and personal VOC concentrations in homes, offices and schools in the metropolitan region of Kocaeli, Turkey. Water, Air, and Soil Pollution, J91(1-4), 113-129.

34. Piscopo, G. (2001). Groundwater vulnerability map explanatory notes, Castlereagh Catchment. NSW Department of Land and Water Conservation, Australia.

35. Pistocchi, A., \& Bidoglio, G. (2009) Is it presently possible to assess the spatial distribution of agricultural pesticides for continental Europe? A screening study based on available data.

36. Pistocchi, A., Luzi, L, \& Napolitano, P. (2002). The use of predictive modeling techniques for optimal exploitation of spatial databases: a case study in landslide hazard mapping with expert-system-like methods. Environmental Geologv, 4l(7), $765-775$.

37. Pistocchi, A., Vizcaino, P., \& Hauck, M. (2010) A GIS modelbased screening of potential contamination of soil and water by pyrethroids in Europe. Journal of Environmental Management. ISSN 0301-4797. doi:10.1016/j.jenvman.2009.05.020.

38. Pistocchi, A., Vizcaino, P., \& Sarigiannis, D. Spatially explicit multimedia fate models for pollutants in Europe: state of the art and perspectives. Science of the Total Environment. doi:10.1016/j. scitotenv,2009.10.046

39. Plackett, R. L., \& Hewlett, P. S. (1952). Quantal responses to mixtures of poisons. Journal of the Roval Statistical Societt: Series $B, 14,141-163$.

40. Price, P. S., Chaisson, C. F., Koontz, M., Wilkes, C., Ryan, B., Macintosh, D, et al. (2003). Construction of a comprehensive chemical exposure framenork using person-oriented modeling. Annandale: The LifeLine Group. 129 pp.

41. Sala, S., \& Vighi, M. (2007). GIS-based procedure for sitespecific risk assessment of pesticides for aquatic ecosystems, Ecotoxicology and Environmental Safety, 69(1), 1-12.

42. Sattler, B., Lippy, B., \& Jordan T. (1997) Hazard communication: a review of the science underpinning the art of communication for health and safety. US Department of Labor, Washington, DC. $\mathrm{http} / /$ www osha.gov/SLTC/hazardcommunications/hc2 inf $2 . \mathrm{htm}$ l. Accessed May 2009

43. Schipper, A. M., Loos, M., Ragas, A. M. J., Lopes, J. P. C., Nolte, B., Wijnhoven, S, et al. (2008). Modeling the influence of environmental heterogeneity on heavy metal exposure concentrations for terrestrial vertebrates in river floodplains. Environmental Toxicologv and Chemistry, 27, 919-932.

44. Schlink, U., Rehwagen, M., Damm, M., Richter, M., Borte, M., \& Herbarth, O. (2004). Seasonal cycle of indoor-VOCs: comparison of apartments and cities. Atmospheric Environment, 38(8), 11811190.

45. Schneider, P., Gebefugi, I., Richter, K., Wolke, G., Schnelle, J., Wichmann, H. E., et al. (2001). Indoor and outdoor BTX levels in German cities. The Science of the Total Environment, 267(1-3), $41-51$.

46. Srivastava, A. (2005). Variability in VOC concentrations in an urban area of Delhi. Environmental Monitoring and Assessment, 107(1-3), 363-373.

47. Tait, N. G., Lemer, D. N., Smith, J. W. N., \& Leharne, S. A. (2004). Prioritisation of abstraction boreholes at risk from chlorinated solvent contamination on the UK Permo-Triassic sandstone aquifer using a GIS. The Science of the Total Enironment, 319, 77-98.
48. Thomas, A., Best, N., Lunn, D., Annold, R., \& Spiegelhalter, D. (2004). GeoBUGS user manual, version 1.2. Cambridge: Medical Research Council Biostatistics Unit; 2004, http $/ /$ www.mrcbsu. cam.ac.uk/bugs/winbugs/geobugs.shtml.

49. Tortell, P. (1992). Coastal zone sensitivity mapping and its role in marine environmental management. Marine Pollution Bulletin. $25,88-93$.

50. Van der Linden, A. M. A., Luttik, R., Deneer, J. W., \& Smidt, R. A. (2004). Dutch environmental indicator for plant protection products. Description of input data and calculation methods. Report no, 716601009/2004, RIVM/Alterra, Bilthoven/Wageningen, The Netherlands.

51. Van der Linden A. M. A., van Beelen, P., van den Berg, G. A., de Boer, M., van der Gaag, D. J., Groenwold, J. G., et al. (2006) Evaluation sustainable crop protection. Report nr. RIVM607016001, RIVM, Bilthoven, The Netherlands.

52. Van der Linden, A. M. A., Luttik, R., Groenwold, J. G., Kruijne en, R., \& Merkelbach, R. C. M. (2008). Dutch Environmental Indicator for plant protection products, version 2. Input, calculation and aggregation procedures, Report nr. 607600002/2008, RIVM, Bilthoven, The Netherlands.

53. Van Leeuwen, C. J., \& Hermens, J. L. M. (1995). Risk assessment of chemicals: An introduction. Dordrecht: KJuwer. $374 \mathrm{pp}$.

54. U.S. EPA (2006). Considerations for Developing Altemative Health Risk Assessment Approaches for Addressing Mutiple Chemicals, Exposures and Effect (External Review Draft). U.S. Environmental Protection Agency, Washington, D.C., EPA/600/R$06 / 014 \mathrm{~A}, 2006$

55. Verro, R., Finizio, A., Otto, S., \& Vighi, M. (2009). Predicting pesticide environmental risk in intensive agricultural areas. II: Screening level risk assessment of complex mixtures in surface waters. Environmental Science \& Technology, 43, 530-53.

56. Verro, R., Finizio, A., Otto, S., \& Vighi, M. (2009). Predicting pesticide environmental risk in intensive agricultural areas. $\mathbf{I}$ : Screening level risk assessment of individual chemicals in surface waters. Environmental Science \& Technolog): 43, 522-529.

57. Vesanto, J. (1999). SOM-based data visualization methods. Intelligent Data Analysis, 3, 11-126.

58. Vesanto, J., \& Alhoniemi, E. (2000). Clustering of the selforganizing map. IEEE Transactions on Neural Networks, 11, 586600 .

59. Wogalter, M. S., Conzola, V. C., \& Smith-Jackson, T. L. (2002). Research-based guidelines for warning design and evaluation. Applied Ergonomics, 33, 219-230.

60. Wood, M., \& Jelínek, R. (2007) Risk mapping in the new member states. A summary of general practices for mapping hazards, vulnerability and risk. Report no. EUR $22899 \mathrm{EN}$, Institute for the Protection and Security of the Citizen, Joint Research Centre, European Commission, Ispra, Italy, 26 pp.

61. Woodbury, P. B. (2003). DOs and DON'Ts of spatially explicit ecological risk assessment. Environmental Toxicologv and Chemistry, 22, 977-982.

62. Worrall, F, \& Besien, T. (2005). The vulnerability of groundwater to pesticide contamination estimated directly from observations of presence or absence in wells. Joumal of Hydrologv, 303, 92-107.

\section{Supporting information}

A document of supporting information is available along with the paper, containing additional material for the illustration of the case studies presented here. 